\title{
"JUDICIALIZAÇÃO DA POLÍTICA": DÉFICITS EXPLICATIVOS E BLOQUEIOS NORMATIVISTAS*
}

\author{
MARCOS NOBRE \\ JOSÉ RODRIGO RODRIGUEZ
}

[*] Texto apresentado na $35^{\mathrm{a}} \mathrm{AN}-$ POCS, Caxambu (MG), 2011, no Fórum "Dilemas da Modernidade Periférica".
[1] Para este ponto, ver o início de Rodriguez, José Rodrigo. “The Persistence of Formalism: Towards a Situated Critique beyond the Classic Separation of Powers", The Law $\&$ Development Review, vol.3, n. 1, 2010.
Nosso objetivo com este texto é mostrar as limitações de uma concepção formalista do direito, calcada na gramática clássica do direito burguês. Isso se faz necessário, a nosso ver, porque essa concepção mostra uma persistência na teoria e na pesquisa social — na brasileira, em especial - que bloqueia, a nosso ver, uma adequada compreensão do direito, entendido tanto em seu sentido de fenômeno social quanto como uma das disciplinas das ciências humanas.

É evidente que tal persistência não é casual e merece ser investigada por si mesma. Esse não é, entretanto, nosso objetivo aqui. Limitamo-nos a dar indicações nesse sentido. Para o caso dos países centrais - em especial para aqueles de tradição jurídica romano-germânica, mas não só - , pensamos que essa persistência se deve à hegemonia ideológica do neoliberalismo nas últimas décadas, cuja visão tradicional do direito se apoia em interesses tão simples e diretos quanto a defesa intransigente de concepções tradicionais do direito de propriedade, das regras de mercado e de um Estado mínimo. Para o caso do Brasil, a hipótese é que, em vista do longo período de governos autoritários e/ou coronelismo ao longo do século XX, o próprio direito burguês aparece como padrão e como novidade, obscurecendo a visão das profundas transformações pelas quais passou o direito ao longo desse mesmo século. Não por último, pensamos mesmo que as transformações atuais tendem a se dar em um sentido bastante diferente do "direito social" do século passado. Mas, como dito, não é nosso objetivo desenvolver em detalhe essas indicações neste texto; ainda que seja necessário apontar desde o início elementos que são importantes pontos de apoio de nosso diagnóstico do tempo presente.

Ao longo do texto, chamaremos a essa concepção formalista do direito simplesmente de "visão normativa", ou, mais precisamente, de "visão normativista" do direito. O formalismo jurídico se tornou ao longo do século Xx quase sinônimo de tudo o que pode haver de cientificamente equivocado e normativamente retrógrado, de modo que é muito raro encontrar quem se reivindique "formalista" ${ }^{1}$. Esse foi o resultado da investida massiva e certeira do movimento operário 
contra o direito burguês clássico, que Weber consagrou com o termo depreciativo de "materialização do direito". Franz Neumann foi um dos primeiros autores a mostrar que o diagnóstico da materialização do direito não era capaz de explicar positivamente o desenvolvimento institucional do começo do século XX. Ao falar em "materialização do direito" sem explicitar sua gênese histórica, Max Weber terminou por naturalizar o código do direito e a enxergar as potenciais mudanças que ele estava sofrendo como se fossem sua destruição. Vejamos.

De acordo com Weber, o direito ocidental é formal, pois permite decidir conflitos a partir de critérios jurídicos, ou seja, com fundamento em normas jurídicas dotadas de racionalidade própria, autônomas em relação a valores morais, éticos, políticos, econômicos etc. O direito ocidental é um direito racional porque remete a justificativas que transcendem o caso concreto por serem baseadas em regras claramente definidas que permitem padronizar as decisões. Historicamente, o desenho institucional que efetivou essas duas ideias nos países foi o Estado de direito concebido em função da teoria da separação dos poderes em que o Judiciário tem a função de aplicar as leis produzidas pelo Parlamento. Há variações nacionais muito significativas nesse desenho, mas para os fins deste texto nos basta esta visão de senso comum, pois, ainda que de maneira transformada, ela está na base de conceitos como "judiciarização da política" ou "ativismo judicial".

Neste texto, quando falarmos em "código do direito" e em suas transformações estaremos falando do direito racional e formal weberiano, concepção que domina a visão mais corrente sobre o direito até os dias de hoje $e^{2}$. De outra parte, quando falarmos em "gramática" ou das "gramáticas do direito", estaremos falando dos desenhos institucionais em que tal código se encontra configurado a cada vez. Mostraremos a seguir que tais desenhos podem ser modificados por dentro em função da dinâmica dos conflitos sociais a ponto de alterar o código do direito, como ocorreu na passagem do estado liberal para o estado social por ação da classe operária. Ao naturalizar a ligação entre código do direito e gramáticas institucionais, o analista deixa de perceber uma tensão fundamental para o processo de institucionalização e transformação do direito. O conceito de "materialização do direito" weberiano padece desse problema.

Ainda de acordo com Weber, o direito materializado é aquele que incorpora raciocínios valorativos que fogem do registro legal/ ilegal por estarem fundados em cláusulas gerais como "boa-fé", "bons costumes", "concorrência desleal", "mulher honesta". Tais cláusulas gerais, muitas vezes contidas nas leis, abririam espaço para a subjetividade do juiz e/ ou para a dissolução do direito em outras ordens normativas.Afinal, de acordo com esse diagnóstico, tais cláusulas permitiriam que os julgamentos fossem proferidos com base em normas
[2] Para indicar que essa visão do Direito não se restringe, no Brasil, à visão mais comum presente nas Ciências Sociais ou no debate público de maneira mais ampla, pode-se mencionar aqui, no campo da Economia, dois influentes artigos a seguir que contêm citações nominais do conceito weberiano: Arida, P., Bacha, E. e Lara-Resende, A. "High interest rates in Brazil: conjectures on the jurisdictional uncertainty". In:Inflation Targeting and Debt: the Case of Brazil. MIT Press, 2005; e Arida, Pérsio. "A pesquisa em direito e em economia", Revista Direito GV 1, pp. 11-22, 2005. Para uma explicação mais completa do conceito de Weber, ver: Weber, Max. Economia e sociedade. Brasília: Editora da UnB, vol. 2, 1999; e Trubek, David. "O direito e a ascensão do capitalismo", Revista Direito GV5, vol. 3, n. 1, 2007. 
[3] Neumann, Franz. The Rule of Law. Political Theory and The Legal System in Modern Society, Leamington: Berg, 1986, p. 44. Em Fuga do Direito (São Paulo: Saraiva, 2009), J. R. Rodriguez, especialmente no capítulo final e na conclusão, essa tensão entre o código do direito e as gramáticas institucionais é apresentada com outra terminologia. Nesse livro fala-se de "forma direito" (no lugar de código do Direito) e em "modelos de juridificação" (no lugar de "gramáticas do Direito"). É importante dizer que essa ideia tem como motivação a crítica de F. Neumann a Marx segundo a qual tal autor teria dado mais atenção aos momentos de ruptura institucional do que à transformação da racionalidade do Direito no interior de uma determinada ordem social.

[4] Idem, ibidem.

[5] O debate posterior mostrou como essa posição também possui caráter etnocêntrico. Ver, por exemplo, Jayasuriya, Kanishka. "Franz Neumann on the Rule of Law and Capitalism: The East Asian Case". Journal of Asia Pacific Economy. Abingdon: Routledge, vol. 2, n.3, 1997, p.357, que aproveita a crítica de Neumann a Weber para explicar a racionalidade do direito no leste da Ásia. Ver também Rodriguez, José Rodrigo, “Inverter o espelho: o direito ocidental em normatividades plurais". In: Reis, Rossana Rocha (org.). Política de direitos humanos. São Paulo: Hucitec, 2010; cuja primeira parte resume o debate sobre o tema no campo do Direito e Desenvolvimento.

[6] Umadescriçãoem grandes linhas desse movimento pode ser encontrada em M. Nobre, "Participação e deliberação na teoria democrática: uma introdução". In: Coelho, Vera Schattan P.e Nobre, M.(orgs.).Participação e deliberação: teoria democrática e experiências institucionais no Brasil contemporâneo. São Paulo: Editora 34, 2004.

[7] Esse tema será discutido com mais detalhes adiante.

[8] Sobre isso, ver novamente o já mencionado "Participação e deliberação na teoria democrática: uma introdução". morais, éticas, religiosas, preceitos científicos etc., fato que colocaria a perder a certeza dos julgamentos padronizados e a autonomia da ordem jurídica em relação às demais ordens normativas.

Franz Neumann mostrou em The Rule of Law (1936) 3 que instituições já atuantes na sociedade estavam contribuindo para compensar a indeterminação das cláusulas gerais e conferir certeza e autonomia para o direito "materializado". As normas processuais que regulavam o procedimento decisório poderiam compensar, segundo Neumann, a indeterminação das normas de conduta4 ${ }^{4}$. Nesse registro teórico, portanto, a materialização deveria ser vista como um índice da transformação da gramática do direito, e não como sua inexorável destruição.

Franz Neumann mostrou também que um dos principais fatores de tal transformação foi a entrada da classe operária no Parlamento, que modificou profundamente as instituições burguesas e sua dinâmica. Nesse sentido, a defesa da manutenção de uma determinada gramática do direito em razão do diagnóstico da materialização terminou por assumir, naquele momento histórico, um sentido claramente conservadors.

O formalismo conseguiu retornar na segunda metade do século $\mathrm{XX}$ sob nova roupagem, a da "técnica". Apesar dos tempos da "técnica e ciência como 'ideologia" terem ficado para trás sob muitos aspectosgraças, em boa medida, ao duro enfrentamento dessa lógica por parte dos chamados "novos movimentos sociais" 6 - é ainda dominante no debate público brasileiro a ideia de que o Judiciário é (e deve ser) o último bastião da "técnica". O que se exige sempre é que a decisão judicial seja uma "decisão técnica", o que significa pouco mais do que dar nova roupagem à velha metáfora formalista do "juiz boca da lei" Esse é o sentido subjacente, portanto, à caracterização que fazemos sob a expressão "visão normativista" do direito.

Note-se, a liás, que tal concepção - como, antes dela, a de Weber - bloqueia a própria compreensão do processo de aprofundamento da democracia vivido nas últimas décadas. Embora não se trate, evidentemente, de um processo linear de progresso, tampouco desprovido de ambiguidades, pode reconstruir esse movimento também como um processo de abertura de novos espaços nos poderes constituídos pelo movimento social organizado. Se o movimento operário obrigou o Parlamento a se abrir à democracia de massas, os chamados "novos movimentos sociais" obrigaram o próprio Estado a se abrir à participação e à negociação de políticas públicas antes apresentadas como "técnicas" e, portanto, "neutras" de espantar, portanto, que esse movimento chegue agora ao Judiciário e que esse poder esteja agora sob a pressão da sociedade civil organizada para se abrir à participação e à deliberação da cidadania, que quer discutir, entre outras coisas, o próprio conceito jurídico de 
legitimidade das partes. Queremos chamar aqui a atenção para o que nos parece ser o grave erro político de não perceber o momento de pressionar o Judiciário para que, de maneira regrada, democrática, se abra à participação cidadã.

Entretanto, se o exemplo que acabamos de dar se refere ao Judiciário, nosso objetivo com este texto não é de maneira alguma restringiro exame a esse âmbito. Ao contrário, pretendemos alcançar aqui o direito entendido como fenômeno social em sentido amplo tanto quanto como disciplina das ciências humanas. Pretendemos entender o direito como fenômeno social não apenas no sentido restrito de suas configurações institucionais fixadas, mas como um processo aberto de disputa pelo sentido da norma, algo que de maneira alguma pode ser reduzido à fixação institucional ou pode ser caracterizado como perda de especificidade do direito em relação às demais ordens normativas. Trata-se apenas do abandono de um padrão tecnocrático na atuação judicial em favor de um modelo de racionalidade aberto à deliberação.

Dito de outra maneira, nosso objetivo é mostrar que uma tal visão normativista do direito, herdeira do formalismo e, a nosso ver, largamente dominante na teoria e na pesquisa social no Brasil, não é capaz de dar conta do direito em pelo menos três sentidos fundamentais. Em primeiro lugar, não compreende o direito em seu código próprio, ou seja, segundo a autonomia queé própria do direito em sociedades modernas e sujeito a transformações capazes de alterar sua racionalidade sem suprimir as fronteiras que o separam das demais ordens normativas. Em segundo lugar, esse déficit estrutural bloqueia o entendimento das diferentes configurações institucionais próprias do direito e veda o acesso a diferentes e alternativas construções institucionais possíveis. Em uma palavra, essa visão naturaliza e torna unívoca a gramática do direito. Por fim, é uma visão do direito que restringe a priori o próprio sentido do que possa ser o "jurídico", fixando de antemão um âmbito para a regulação jurídica que impede o acesso às disputas contemporâneas pela pluralização no interior do próprio código do direito, que se desdobra na criação de novas gramáticas institucionais, novos modelos institucionais que entram em tensão constante com o código do direito. Não por acaso, é uma visão que exclui das categorias fundamentais de análise a de "esfera pública", de decisiva importância para apreender o processo em toda a sua complexidade e potencialidades de transformação.

A mera exposição do objetivo do texto, entretanto, é suficiente para indicar a impossibilidade de demonstrar todos esses elementos em sua devida amplitude no âmbito de um artigo. Por essa razão, decidimos limitar essa demonstração a propósito daquela noção que nos parece ser a dominante no pensamento social do direito e sobre o direito no Brasil: aquela de "judicialização da política". Por meio da 
análise dos pressupostos e implicações dessa noção - e daquela que consideramos sua contraparte necessária, a noção de "ativismo judicial" - pretendemos mostrar tanto os déficits explicativos como os bloqueios a possíveis transformações progressistas do direito no país. Nossa argumentação tem como ponto central a total exterioridade dessas noções em relação ao código do direito. O que, não por último, significa também uma exterioridade em relação ao próprio direito como disciplina científica das ciências humanas.

[9] "Sentidos da judicialização da política: duas análises". Lua Nova, n. 57, 2002, em que são analisados os livros: Vianna, Luís Werneck (org.). A democracia e os três poderes no Brasil. Belo Horizonte: Editora UFMG, 2002; Arantes, Rogério Bastos. Ministério Público e politica no Brasil. São Paulo: Sumaré, 2002.

[10] Deixamos de lado neste texto o aspecto complementar envolvido nesse posicionamento ideal central do Parlamento em uma democracia, ou seja, o da teoria da representação política que pressupõe.Apesar de não examinarmos esse outro forte pressuposto normativo, é possível pelo menos adiantar o que nos parece ser o estado problemático dessa concepção de representação mediante duas referências bibliográficas que o colocam em xeque. De um ponto de vista mais teórico, o livro de Nadia Urbinatti, Representative Democracy: Principles and Genealogy. Chicago: Chicago UP, 2006, no qual a ideia de uma representação "advocatícia" pode ser interpretada como uma abertura para diferentes tipos, formas e formatos de representação contra "o mero registro de uma configuração social dada" (p. 46) que continua a sustentar o pressuposto de que o Parlamento dever ser o centro, a fonte e o modelo de toda representação, normalmente identificada com a "vontade geral" ou alguma variante dessa noção. Do ponto de vista da ligação entre bases teóricas e pesquisa empírica, muitas indicações interessantes da pluralização da representação podem ser encontradas em Lavalle, Adrián Gurza, Houtzager, Peter P. e Castello, Graziela. "Democracia, pluralização da representação e sociedade civil". Lua Nova, n. 67, 2006. $\star \star \star$

Só faz sentido falar em "judicialização da política" ou em "ativismo judicial" tendo por padrão uma teoria normativa da política que se apoia em uma concepção bastante particular da separação de poderes em um Estado de direito. Dessa perspectiva, embora aparentem ser ideias bastante diferentes entre si, "judicialização da política" e "ativismo judicial" são como lados de uma mesma moeda, de um mesmo processo visto ora da perspectiva da política que seria "invadida" pela lógica judicial, ora da perspectiva do próprio "invasor". Nesse caso, a ligação entre os dois momentos está posta em uma visão em que o Legislativo deve ser o centro vivo de um Estado Democrático de direito, tanto a sede por excelência da política quanto seu real ativista.

Partimos aqui de duas ideias presentes em um comentário de Débora Alves Maciel e Andrei Koerner9: tanto dos diferentes pontos de partida normativos de cada noção particular de "judicialização da política" quanto da disseminação dessa ideia em diferentes sentidos e acepções no debate público em sentido amplo. Não pretendemos examinar nenhuma concepção particular de "judicialização da política”, mas aquele que nos parece ser o núcleo normativo fundamental de qualquer de suas versões. E acrescentamos aqui a noção de "ativismo judicial" como seu avesso complementar.

De saída, consideramos que tal visão normativa não é capaz de demonstrar sua aderência à realidade; por essa razão dizemos que se trata, na verdade, de uma visão normativista do direito que naturaliza sua gramática institucional e não abre espaço para a transformação do código do direito. Tanto do ponto de vista de sua capacidade explicativa como de seu enraizamento na realidade social contemporânea. Uma visão normativa forte como essa pode perfeitamente se manter como "ideal" a ser perseguido pelos atores sociais. Mas não pode servir de base a um diagnóstico do tempo presente. E permanece como um "ideal" no sentido utópico da expressão, já que não está em condições de mostrar quais elementos concretos da atual configuração do Estado Democrático de direito poderiam ser mobilizados pelos atores sociais para atingir o objetivo de fazer do Parlamento o efetivo centro da política ${ }^{10}$. 
Não se trata aqui de discutir se tal modelo estilizado de separação de poderes que se cristalizou no século XIX de fato funcionou em algum lugar segundo os parâmetros normativos que o justificavam. Independentemente do fato de ter um dia funcionado assim ou não, o modelo padrão de separação de poderes certamente não operou nas últimas décadas do século $\mathrm{XX}^{11}$. Apenas para tomar como exemplo um estudo recente, mas já considerado clássico, em "The New Separation of Powers" ${ }^{12}$, Bruce Ackerman compara a tradição americana de separação de poderes com o modelo de países como Alemanha, Itália, Japão, Índia, Canadá e África do Sul para criticar os EUA e argumentar contra a exportação de seu modelo para outros países do mundo. Na descrição do autor, esse modelo possui um presidente eleito que funciona como freio e contrapeso do congresso eleito democraticamente. Ackermann defende um modelo em que o primeiro-ministro fique no cargo desde que consiga mantero apoio do Parlamento eque o poder do Parlamento tenha como freio e contrapeso uma série de instituições, não apenas a corte constitucional. Para o autor, esse modelo teria se mostrado superior ao modelo americano por ser capaz de criar uma grande variedade de estratégias institucionais com o objetivo de efetivar os três princípios que motivam a moderna doutrina da separação de poderes: democracia, profissionalismo e proteção dos direitos humanos.

Independentemente do mérito das propostas de Ackerman, o que nos importa em seu artigo é tomá-lo como ilustração dos dois aspectos de nossa argumentação aqui. Serve para mostrar a variedade não só de desenhos institucionais concretos da separação de poderes, mas igualmente de modelos normativos possíveis; ao mesmo tempo mostra o quanto é problemático fixar de antemão um desenho determinado da separação de poderes, que passa a ser pensado como modelo a ser seguido ou mesmo "copiado". A cristalização da visão de que os poderes são três e que cada um deles tem a função de controlar o outro é apenas uma das possibilidades institucionais que mesmo a ideia original de freios e contrapesos de Montesquieu permite pensar. $\mathrm{O}$ sentido de $O$ espírito das leis nunca foi afirmar os três poderes, Legislativo, Executivo e Judiciário, como a essência do Estado de direito, mas sim mostrar que é necessário criar poderes e contrapoderes para evitar a constituição de polos de poder absolutos, sem nenhum controle. Não é necessário que os poderes sejam três e que funcionem de acordo com a lógica naturalizada da separação de poderes. O ponto central é armar uma trama institucional que não admita o arbítrio, independentemente de qual desenho sevenha a adotar. Por isso mesmo, é importante recuperar o espírito da obra de Montesquieu para refletir melhor sobre a dinâmica institucional contemporânea ${ }^{13}$. Além disso, como afirmou Franz Neumann em sua introdução a Oespírito das leis de Montesquieu, a separação de poderes pode funcionar como obstáculo
[11] Sobre a impertinência do conceito tradicional de separação de poderes para a concepção mais contemporânea de racionalidade jurisdicional, ver Rodriguez, José Rodrigo. "The Persistence of Formalism...", op.cit.

[12] Harvard Law Review, vol.113, n. 3, jan. 2000 .

[13] Nesse sentido, ver: Castro, Marcus Faro de. "Jurisdição, economia e mudança social”. Revista EMARF, Cadernos Temáticos, Rio de Janeiro, pp. 143-73. 
[14] Neumann, Franz. "Montesquieu". In: Democratic and Authoritarian State. Glencoe: The Free Press, 1957

[15] Em Fuga do Direito, já citado,J. R. Rodriguez tira diversas consequências dessa afirmação de F. Neumann para a interpretação do código do direito contemporâneo. Em sentido diverso, Althusser, apoiado em C. Eisenmann, contesta o "mito" da separação de poderes em Montesquieu, apontando para o problema de saber "a quem aproveita" tal divisão. Cf.Montesquieu: a política e a história. Lisboa: Editorial Presença, 1972, especialmente o cap. V. A interpretação de Neumann nos parece superior à de Althusser, tanto em termos de exegese quanto de consequências emancipatórias, porque vê um vínculo interno entre direito e democracia que não pode ser encontrado na interpretação althusseriana de Montesquieu. Mas a interpretação de Althusser tem o mérito de enfatizar o caráter de classe de uma determinada interpretação da separação de poderes, ressaltando assim, de outra maneira, o aspecto normativo implícito na ideia de "judicialização da política" que buscamos explicitar aqui.

[16] Um estudo empírico de grande importância para a relativização da tese mais geral da "judicialização" pode ser encontrada em Carlos Ari Sundfeld et al., Controle de constitucionalidade e judicialização: o STF frente à sociedade e aos Poderes, Belo Horizonte: Faculdade de Filosofia e Ciências Humanas, 2010. Entre outras coisas, o estudo inova ao investigar o problema da perspectiva do próprio código do direito e não de um ponto de vista que lhe seria externo. Além disso, aceita em certo sentido o desafio posto pelo mencionado comentário de Débora Alves Maciel e Andrei Koerner de que uma investigação da "judicialização da política” seria dificilmente realizável em termos empíricos.

[17] Esse argumento também vale para as regras jurídicas e sua utilização para a solução de casos concretos como mostraram muito bem Hans Kelsen, Duncan Kennedy e Ronald Dworkin. Ver: Kelsen, Hans. Teoria pura do Direito. Coimbra: Armênio Amado, 1979 (capítulo final); Kennedy, Duncan. "Legal Formality", 2 Journal of Legal Studies 351, 1973; e para as transformações sociais ${ }^{14}$ quando pensada como um modelo normativo destinado a "enquadrar" o conflito social em uma gramática imune à contestação pelas forças progressistas ${ }^{15}$. O significado da separação de poderes e, por conseguinte, o do conceito de Estado de direito, também precisam entrar em disputa.

Nos EUA, por exemplo, grande parte dos avanços no campo social foi efetivada no Judiciário e não no Parlamento. Nesse país, a crítica ao suposto "ativismo judicial" e ao suposto desrespeito ao "espírito da constituição", segundo a palavra dos "pais fundadores", têm funcionado como arma utilizada pelo conservadorismo para barrar tais avanços e colocar a sociedade civil em seu "devido lugar", ou seja, na mão dos lobbies que atuam no Parlamento.

No Brasil, o momento é de redesenho das instituições em todos os níveis, desde a abertura do Executivo para a participação popular direta por meio de conselhos variados, conferências nacionais e agências reguladoras, até a mudança de função do Poder Judiciário, cada vez mais ativo na arena política pela escolha entre as várias alternativas técnico-jurídicas definidas em função do material normativo e do contexto de cada decisão. Nesse contexto, definir a priori a dinâmica institucional em termos normativos a partir de uma concepção modelar da separação de poderes antes bloqueia a compreensão e mesmo a possibilidade de que a sociedade se aproprie de instituições em construção e mutação. E acaba por obscurecer tanto o lugar e a função efetivos do Poder Judiciário, do Poder Executivo e do Poder Legislativo, como encobre as possibilidades institucionais concretas presentes no momento atual ${ }^{16}$.

A predeterminação das fronteiras entre os poderes, de seus domínios próprios e das vias de circulação das demandas sociais parte do pressuposto de que as regras estão predefinidas relativamente aos conflitos e ao "jogo democrático". Pressupõe-se uma noção de "regra" em que esta vem sempre dada em todas as suas consequências, o que inclui o resultado de sua aplicação. É uma acepção de "regra" como estrutura que precedee determina por completo o caso concreto, como deveria ocorrer, segundo essa concepção, em um Estado de direito consolidado. No entanto, é justamente neste ponto que a metáfora da democracia como um "jogo" cujas regras (entendidas nesses termos) estão definidas de antemão começa a atrapalhar o raciocínio e não a esclarecer o problema. É mais adequado deixar essa metáfora de lado.

A concepção de que a regra contenha nela mesma toda a dinâmica institucional e determine de antemão seu desenvolvimento efetivo, assim como a ideia de uma "regra do jogo" cujo sentido seria sempre estável e inequívoco, antes encobrem do que mostram a dinâmica institucional concreta e o funcionamento da democracia ${ }^{17}$. À exceção das regras que exigem que o poder justifique racionalmente suas decisões 
perante a sociedade e atribui à sociedade a possibilidade de participar de sua elaboração, um Estado de direito democrático não pode bloquear a disputa pelas regras que definem gramáticas institucionais, sob pena de naturalizar posições de poder político, econômico e social. Mas mesmo as regras de justificação e de autoria das normas podem ser desenhadas das mais diferentes maneiras, podem conter diversas variantes, há sempre várias maneiras de fundamentar uma decisão e esta também é uma arena aberta à disputa ${ }^{18}$.

Se existe um núcleo normativo próprio da democracia, ele está antes no princípio de que a dinâmica institucional deve poder ser colocada em questão em todos os seus diferentes momentos, em seus diferentes desenhos, um questionamento que deve poder ser levado a seus limites tanto por demandas concretas dirigidas a este ou aquele órgão, como na dimensão mais abstrata do debate acadêmico, ou do questionamento judicial e da disputa legislativa. Subtrair tais regras ao debate significa conservar e naturalizar uma determinada distribuição de poder entre grupos e uma determinada forma de mediar a relação entre Estado e sociedade. É um procedimento que impede compreender adequadamente a dinâmica institucional: as assim chamadas "regras do jogo" e também o que chamamos de "código do direito" são apenas abstrações da dinâmica institucional isolada em um de seus aspectos em um determinado ponto do tempo e do espaço. O desfecho do processo não pode ser conhecido de antemão. $O$ mero ato de identificar a regra e apresentar a racionalidade do suposto "jogo" já é um ato interessado e precisa ser posto em evidência junto com qualquer suposta "definição" da regra.

A visão por demais normativa de política que sustenta as ideias gêmeas de "judicialização da política" e de "ativismo judicial" carrega consigo uma compreensão limitada do código próprio do direito, não por último da própria CF de 1988. Na verdade, trata-se de uma visão que procura limitar normativamente o âmbito de aplicação do direito porque, em suas análises, não se dedica a compreender o código que lhe é próprio. Se o fizesse, poderia encontrar as reais limitações impostas por esse código. E, igualmente, poderia enxergar os potenciais de transformação que ele carrega. $O$ normativismo próprio das noções de "judicialização da política" e de "ativismo judicial" vê o espaço jurisdicional como infenso à política em sentido amplo, o que corresponde ao preconceito mais geral de que o Judiciário como instituição é uma "caixa-preta". Ou seja, uma incompreensão do código do direito e de sua lógica de funcionamento e transformação se transforma em uma acusação de "intransparência", de tal maneira que os reais momentos de intransparência do funcionamento do Judiciário são antes encobertos do que revelados por essa atitude teórica e prática.
Dworkin, Ronald. O império da lei. São Paulo: Martins Fontes, 1999. É importante dizer que nenhum dos autores citados tira todas as consequências de sua visão da racionalidade jurisdicional para a concepção de Poder Judiciário e de separação de poderes que seu pensamento pressupõe. A renovação da teoria do Direito no que diz respeito à racionalidade jurisdicional ainda é uma tarefa a ser feita. Sobre esse ponto, ver a parte final de Rodriguez, J. R. "The Persistence of Formalism...”, op. cit.

[18] Para este ponto, ver: Machado, M., Püschel, Flavia Portella, Rodriguez, J. R. "The Juridification of Social Demands and the Application of Statutes: an Analysis of the Legal Treatment of Antiracism Social Demands in Brazil", Fordham Law Review, v. 77, pp. 1535-58, 2009; e Rodriguez, J. R., Püschel, F. P. “Inveja de Sísifo: a dogmática jurídica entre tradição e inovação". In: Rodriguez, J. R., Batalha, Carlos Eduardo e Barbosa, Samuel Rodrigues (orgs.). Nas fronteiras do formalismo. A função social da dogmática jurídica hoje. São Paulo: Saraiva, 2010, pp. 299-310. 
[19] Brown, Wendy e Halley, Janet (orgs.). Left Legalism/Left Critique, Durham. NC: Duke University Press, 2002.

[20]Em uma resenha crítica ao livro de Andrei Y. Vyshinsky, The Law of Soviet State, publicada em 1949 , Franz Neumann mostra que as supostas inovações do direito soviético após a Revolução Russa não passavam da repetição ligeiramente modificada das categorias jurídicas burguesas, ou seja, que imaginação institucional e revolução não andam necessariamente juntas. Ver Political Science Quartely, vol. 64, n. 1, mar. 1949, pp. 127-31.

[21] Essa formulação, bastante influente no Brasil, foi proposta por Celso Lafer a partir de sua interpretação da obra de Hanna Arendt. Ver: Lafer, C. "A reconstrução dos direitos humanos: a contribuição de Hannah Arendt", Estudos avançados, 11 (30), 1997.

[22] Como exemplos do formato mais comum dos debates sobre a reforma do Poder Judiciário, pode-se citar o "I Pacto de Estado em favor de um Judiciário mais rápido e republicano", de 2004, e o "II Pacto republicano de Estado por um sistema de justiça mais acessível, ágil e efetivo", de 2009 (ambos no <portal.mj.gov. br>, acessado em 02/11/2011), celebrados pelos chefes dos três poderes da República brasileira.
É esse modo de encarar o Judiciário que vê o ato de julgar como um procedimento que não apenas seria meramente técnico, mas que também deve sê-lo, sem ligação alguma com o conflito social e com os debates na esfera pública. E aqui está justamente o normativismo dessa visão do Judiciário: o ideal se transforma em uma definição a-histórica e descontextualizada do significado das instituições. A naturalização conceitual que apresenta nesses termos em análises políticas de conjuntura e trabalhos acadêmicos variados é um verdadeiro desastre para o pensamento crítico e para a dinâmica das forças sociais progressistas.

O livro Left Legalism/Left Critique ${ }^{19}$, por exemplo, é um acerto de contas duro e profundo de diversos autores de esquerda com a gramática institucional norte-americana. O sentido geral do livro é mostrar como a esquerda caiu na armadilha desse normativismo, perdendo em contundência e radicalidade. $O$ livro é especialmente interessante, pois, em vez de propor como alternativa a destruição violenta das instituições postas, faz um apelo à imaginação institucional dirigida a inventar novas maneiras de juridificar o conflito social sem utilizar a linguagem tradicional dos direitos e deveres ${ }^{20}$. Nesse sentido, a visão da cidadania como "direito a ter direitos" ${ }^{21}$, também está caduca e deve ser deixada de lado. A cidadania é bem mais do que isso. Ser cidadã é ter a possibilidade de tomar parte ativa no processo de definição da gramática institucional, mesmo que seja para além da linguagem dos direitos. Ou seja, ser cidadã é ter a possibilidade de exercitar e efetivar deliberativamente a imaginação institucional.

O debate sobre a reforma do Poder Judiciário no Brasil, por exemplo, tem se concentrado principalmente nas questões da celeridade da prestação jurisdicional e na garantia de acesso à justiça à população brasileira. De acordo com essa agenda, é preciso modernizar nossos códigos de processo, aumentar o número de juízes e melhorar a gestão interna do Poder Judiciário para garantir sentenças mais rápidas. Além disso, o país, segundo o raciocínio dominante, precisaria ampliar a oferta de mecanis mos de solução de conflitos (juizados especiais, mediação, conciliação) e o acesso a advogados e defensores públicos para permitir que os mais pobres utilizem o Judiciário para resolver seus problemas ${ }^{22}$.

Esse debate tem se desenrolado tendo como referência central o Poder Judiciário e o processo judicial como principal meio de solução de conflitos. Discute-se a necessidade de expandir o raio de atuação desse poder, de ampliar o acesso à justiça e de aumentar sua eficiência, sem colocar em questão a gramática dos meios formais para a solução de conflitos utilizados no Brasil. Por exemplo, o tema dos mecanismos alternativos de solução de conflitos tem sido discutido no contexto da reforma do Poder Judiciário e não como 
uma real alternativa a ele ${ }^{23}$. Tais mecanismos têm sido mantidos sob o controle desse poder e tratados, na maior parte das vezes, como instrumentos destinados a desafogar o Judiciário. Reduzir os meios alternativos a essa função meramente instrumental significa deixar de lado sua capacidade de enquadrar os conflitos de outra maneira e promover a mediação entre sociedade e Estado de acordo com outra gramática. Uma outra gramática que pode bem receber o nome de "direito", desde que se deixe de pensar o jurídico como sinônimo de "judicial" e se deixe de pensar os avanços constitucionais apenas como a ampliação do acesso à justiça vista como sinônimo de "Poder Judiciário". Esse exemplo nos parece trazer um elemento adicional à argumentação de como a cristalização de uma determinada visão e institucionalidade do direito prejudica não apenas a compreensão do funcionamento concreto das instituições, mas também suas potencialidades de transformação. Porque o que está em jogo aqui é o próprio sentido do que deve ou não ser denominado "jurídico": é o sentido mesmo do direito que está em causa.

Mas nosso objeto neste texto está bastante aquém dessa posição do problema. As ideias gêmeas de "judicialização da política" e de "ativismo judicial" representam um imbróglio teórico-político que nem sequer tem acesso à sua própria concepção de uma linguagem dos direitos que não se pluralizou. Esse problema permanece inteiramente obscurecido por uma rígida fixação institucional que ocupa todo o primeiro plano de sua concepção normativa. De modo que, para evitar o imbróglio, a primeira atitude a tomaré separar analiticamente os elementos ali amalgamados e afastar o pesado fardo de seus pressupostos normativos. Só assim nos parece possível compreender com um mínimo de clareza o que está em jogo hoje na posição que ocupam o Judiciário e o direito na política brasileira em sentido amplo.E, quem sabe, chegar mesmo a abrir futuramente a discussão sobre a pluralização da linguagem do direito e dos direitos.

Tudo isso não significa que não seja compreensível que a confusão tenha se instalado nesses termos na discussão. A desconfiança em relação ao direito é própria de um país com parca cultura política democrática, marcado por sucessivos governos autoritários e/ou oligárquicos no século XX. Da mesma forma, do outro lado da moeda, é igualmente compreensível que um país em democratização recente veja a promulgação de leis (e o exemplo máximo aqui é a CF de 1988) como ponto de chegada para a solução de problemas e satisfação de demandas legítimas, o que leva à "decepção" correspondente de essas mesmas leis "não serem aplicadas". Ou seja, de um lado, o direito évisto com suspeição. De outro, é visto como solução para todos os males. E, quando não traz a solução esperada, cai novamente no elemento da suspeição, em um círculo enganoso.
[23] A bibliografia sobre todos esses temas é imensa e muito diversa. Nossas afirmações aqui se referem apenas à tópica mais comum presente no debate público de maneira mais ampla e não pretendem dar conta da complexidade da produção científica sobre essas questões. 
[24] Ver a esse respeito Nobre, M. "Apontamentos sobre a pesquisa em direito no Brasil". In: Fabiani, Emerson Ribeiro (org.). Impasses e aporias do direito contemporâneo: estudos em homenagem a José Eduardo Faria. São Paulo: Saraiva, 2011. Sobre a implantação da universidade brasileira contra o bacharelismo, ver ainda Nobre, M. e Terra, Ricardo. Ensinar filosofia: uma conversa sobre aprender a aprender. Campinas: Papirus, 2007, especialmente a parte I.
Do ponto de vista da produção acadêmica, a situação é bastante semelhante. O padrão universitário que se estabeleceu no país teve em larga medida como inimigo e como alvo o tipo de produção acadêmica tradicionalmente apresentada pelo direito como disciplina do conhecimento. Por terem se instalado cem anos antes do projeto universitário implantado no século Xx, as faculdades de direito e seu típico "bacharelismo" dispuseram até pelo menos a década de 1930 de certa primazia na definição dos padrões universitários em ciências humanas. Esse predomínio foi severamente contestado com a introdução de padrões de produção de conhecimento próprios de uma universidade "moderna", que se opunha ao "arcaísmo" dos bacharéis, não por último pela relação promíscua que mantinham com o poder estabelecido. Eé incontestável que o direito como disciplina acadêmica até hoje não conseguiu acompanhar o rápido desenvolvimento das demais ciências humanas, especialmente nas últimas décadas do século XX²4. Não faltam, enfim, razões históricas para a imagem distorcida e confusa do direito, seja como fenômeno social, seja como disciplina acadêmica. $O$ estranho é que essas razões insistam em se manter e se reapresentar mesmo quando o fundo histórico que as sustentava já não existe. E as ideias gêmeas de "judicialização da política" e de "ativismo judicial" são apenas uma versão reciclada desse antigo estado de coisas.

Em outras palavras, já dispomos de suficiente experiência democrática para saber que o direito como fenômeno social não pode ser reduzido a uma simples "voz do poder", mas que é uma etapa decisiva da disputa política entendida em sentido amplo. Já dispomos de suficiente experiência democrática para saber que a disputa nos termos do código jurídico tem uma autonomia e uma especificidade que não permitem que ela seja reduzida sem mais a qualquer outro tipo de racionalidade. Dispomos de suficiente experiência democrática para saber que o aprofundamento do Estado de direito caminha junto com a ampliação de direitos, que a "juridificação" das relações sociais é inseparável de avanços em termos institucionais e de cultura política democrática. Também dispomos até de centros produtores de conhecimento jurídico que não mais se pautam pela confusão típica do bacharelismo seja com o poder constituído, seja com a prática profissional dos operadores do direito. E, no entanto, a lógica, a autonomia e a especificidade próprias do código do direito continuam a ser desconsideradas por grande parcela não só dos atores sociais, mas também dos cientistas sociais.

O problema é, de fato, o da devida compreensão dos diferentes processos de "juridificação" das relações sociais, uma perspectiva que permite uma análise bem mais ampla e complexa do papel do direito do que a limitação representada pelas ideias de "judicialização da política" e de "ativismo judicial". A correta compreensão do código do 
direito e de seu papel estruturante na dinâmica institucional permite primeiramente o acesso àquele queé o núcleo social mais profundo da lógica jurídica: seu papel de "transformador"25. De um lado, o direito formata de maneira decisiva demandas sociais de transformação, obrigando os diferentes indivíduos, grupos e movimentos sociais a traduzir suas aspirações em termos jurídicos, o que pode resultar na renovação da gramática institucional e, até mesmo, na transformação do código do direito. De outro lado, essa lógica estruturante do direito exclui de fato opções, alternativas e demandas que não se veem respaldadas na tradução para o código jurídico vigente.

Uma apresentação do papel social do direito que esteja à altura da complexidade do fenômeno tem de ser capaz de manter essas duas perspectivas simultaneamente. Aliás, essa dupla perspectiva é também condição necessária para uma visão crítica do direito. Pois, de um lado, permite examinar a juridificação em sua especificidade e lógica próprias, mostrando a ligação íntima entre o enorme peso do direito no mundo contemporâneo e o código que lheé próprio. De outro lado, permite mostrar os limites do direito e de seu código, apontando para todos os processos sociais excluídos pela juridificação nos termos do código vigente. Essa abordagem em dupla perspectiva é importante entre outras coisas porque veda as interpretações unilaterais que acabam por fazer do direito um "supermédium" de coordenação das ações sociais. Desnecessário dizer que uma investigação como essa só pode ser de fato realizada se a pesquisa em direito for realizada em colaboração com as demais ciências sociais ${ }^{26}$.

Um exemplo simples e conhecido de muitos é a greve e a possibilidade de organizar sindicatos. No final do século XIX e começo do século XX a greve e a liberdade sindical eram vistas como fatos ilícitos punidos inclusive pelo direito penal. As forças conservadoras da época defendiam uma visão do código do direito que via a organização de sindicatos e a realização de greves como um atentado ao direito de propriedade e ao cumprimento dos contratos celebrados entre empregados eempregadores. Dessa forma, a assim denominada "questão social" ficava localizada fora das instituições políticas normais, relegada aos domínios do ilícito e do crime.

Do ponto de vista do código do direito da época e das instituições que o efetivaram, a questão social só podia ser figurada como um desrespeito ao Estado de direito. Para que a questão social aparecesse como tal foi preciso abordá-la do ponto de vista de outras ciências, por exemplo, a ciência da história. Friedrich Engels em seu estudo clássico sobre "A situação da classe trabalhadora na Inglaterra" 27 foi um dos autores que levou adiante essa tarefa e contribuiu para que a questão social e o sofrimento humano que ela embutia viesse à luz sob outra roupagem.
[25] Essa ideia tem como ponto de partida a já mencionada obra de Habermas, Direito e democracia. Ainda que não partilhemos de todos os pressupostos e consequências que sustentam a posição de Habermas, não cabe aqui, entretanto, tratar especificamente dessas diferenças. Limitamo-nos a indicar os pontos de divergência mais relevantes: o do peso a nosso ver excessivo que adquire o Direito como "médium" na obra mais recente de Habermas; e a própria justificação habermasiana para a separação de poderes, colocada aqui em questão a propósito da "visão normativista” do Direito e da política.

[26] Uma tentativa de pensar o Direito criticamente nesses termos está no cap. 3 da obra já citada, Fuga do Direito.
[27] Engels, Friedrich, A situação da classe trabalhadora na Inglaterra. São Paulo: Boitempo, 2008. 
[28] Kahn-Freund, Otto, "Das soziale Ideal des Reicharbeitsgerichts".In: Ramm, Thilo (org.). Arbeitsrecht und Politk. Neuwied: Luchterhand, 1966.

[29] Em Rodriguez, J. R. Dogmática da liberdade sindical, Rio de Janeiro: Renovar, 2003, afirma-se que a proteção social consagrada no direito é vista como uma espécie de "dano essencial" à racionalidade do livre mercado que nunca foi esquecida ou vista como normalidade institucional pelas forças conservadoras, que sempre contestaram e combateram os institutos do assim denominado Welfare State.

[30] In: Kübler, Friedrich (org.). Verrechtlichung von Wirtschaft, Arbeit und sozialer Solidarität. Frankfurt/Main: Suhrkamp, 1985.
E foi necessária muita luta social para que a gramática institucional se transformasse e, nesse caso, que transformasse o código do direito a ponto de incluir essa questão em seu interior, com a criação de novos conceitos jurídicos e de um novo modelo de Estado. A par da batalha social nas ruas, foi travada uma batalha dogmática e uma disputa em torno do desenho institucional no interior do código jurídico para que fosse possível criar pouco a pouco um novo modelo de juridificação que considerasse a greve e a possibilidade de organizar sindicatos como fatos lícitos. Um retrato dramático desse processo pode servisto no texto de Otto Kahn-Freund, "O ideal social das cortes do Reich", de $1931^{28}$, em que o autor mostra como os juízes alemães se recusavam a admitir e aplicar os novos institutos do direito do trabalho consagrados pela Constituição de 1918. Nesse momento, para o código jurídico como concebido pelas forças conservadoras, a proteção social adquiria características disformes, impensáveis.

O resultado final desse embate foi a transformação radical da compreensão burguesa dos contratos, do direito de propriedade, do Estado e do direito. O direito do trabalho e o Estado social, hoje vistos como coisa natural, nasceram como um escândalo aos olhos burgueses e como uma afronta ao Estado de direito e ao conceito de direito. Seu poder subversivo permanece vivo aos olhos das forças neoliberais, fundadas na economia neoclássica, que continuam saudosas da gramática clássica do direito burguês ao se apresentarem como defensoras intransigentes do estado mínimo 29 .

Uma concepção tradicional do direito como a que sustenta as ideias de "judicialização da política" e de "ativismo judicial" veda o acesso a esses processos simultâneos de tradução e de exclusão próprios da juridificação. Mais que isso, essa concepção congela o direito e seu código de tal maneira que a própria possibilidade de pensar a regulação jurídica de conflitos sob novas formas sociais, legais e institucionais desaparece do horizonte dos atores. Um entendimento não tradicional do direito e de seu papel social permite recolocar o problema de fundo presente nas ideias gêmeas de "judicialização da política" e de "ativismo judicial" em termos mais frutíferos.

A discussão sobre a juridificação vem já de há muito tempo. Seu ápice se deu na década de 1980, em conjunção principalmente com o debate em torno do Welfare State europeu. O texto considerado clássico sobre o assunto é o de Teubner, "Verrechtlichung - Begriffe, Merkmale, Grenzen, Auswege" ${ }^{\circ}$. Nesse artigo, o autor elabora seu famoso "trilema regulatório", que procura organizar diversos problemas do direito contemporâneo, a saber: (a) tendência à indiferença recíproca entre direito e sociedade; (b) perigo de colonização da sociedade pelas leis; e (c) desagregação do direito pela sociedade. 
Trocando esse diagnóstico em miúdos, pode-se dizer, com Teubner, que a complexidade da sociedade dificulta cada vez mais a regulação. A regulação jurídica põe em risco a identidade e a autenticidade das relações sociais pelo uso de categorias que perdem em abstração e passam a regular diretamente as diversas formas de vida, danificando seu funcionamento. Ainda, a proliferação da regulação de inúmeros objetos, a "inflação legislativa", faz com que o direito perca em organicidade e coerência interna, o que dificulta lidar com os conflitos sociais por meio de um conjunto articulado de premissas decisórias. A questão é, evidentemente, que esse diagnóstico também se fixa na gramática do direito que naturaliza a separação de poderes e sua função, sem abrir espaço para interpretar essa suposta "crise do direito" como indício da transformação de seu código. Utilizamos juridificação aqui no sentido mais largo e amplo de "tradução para o código do direito", de tal maneira que todos os diferentes sentidos apontados por Teubner possam ser reunidos sem se excluírem mutuamente.

Em um sentido bastante importante, a conjunção histórica do declínio do Welfare State europeu e do debate sobre a juridificação diz respeito à situação brasileira. Não porque uma rede de proteção social dessa magnitude tenha se estabelecido por aqui, mas porque o fenômeno da juridificação das relações sociais tomou proporções de grande magnitude após a promulgação da CF de 1988, especialmente a partir da segunda metade da década de 1990 . Ou seja, um processo de relativa estabilidade democrática e institucional deu as condições para que dispositivos constitucionais e toda uma nova legislação infraconstitucional pudessem se efetivar, expandindo enormemente o alcance da regulação jurídica de relações sociais.

E o momento presente tem ainda outras especificidades que precisam ser tomadas em conta para produzir um diagnóstico que possa dar conta das figuras atuais da juridificação, o que deve permitir recolocar em novos termos os problemas visados pelas ideias de "judicialização da política" e de "ativismo judicial". Gostaríamos de destacar pelo menos dois elementos que parecem centrais.

Em primeiro lugar, o texto constitucional conseguiu fincar raízes no sistema político e na sociedade de maneira mais ampla. Pode parecer uma obviedade que os mais diferentes atores, defendendo posições incongruentes e incompatíveis entre si, reivindiquem-se da CF para sustentá-las. É preciso lembrar que a crítica de que a Constituição é um "conto de fadas" foi repetida de maneira massacrante durante pelo menos os dez anos que se seguiram à sua promulgação. Uma crítica que, à maneira das ideias de "judicialização da política" e de "ativismo judicial", não vê que o próprio processo de interpretação e de efetivação da Constituição é um processo político cujo resultado não está predeterminado pelo texto mesmo. 
[31] Entre muitos outros aspectos, é fundamental aqui o mencionado estudo Sundfeld, Carlos Ari et al. Controle de constitucionalidade e judicialização: o STF frente à sociedade e aos Poderes, op.cit.

[32] Ver a esse respeito Nobre, $M$. "Indeterminação e estabilidade: os 20 anos da Constituição Federal e as tarefas da pesquisa em direito". Novos Estudos Cebrap, n. 82, nov. 2008.
Mas nem mesmo a ampla legitimidade de que desfruta a CF significa que seu sentido esteja fixado. Pelo contrário, observa-se em anos recentes que o STF mais e mais se retira de seu papel de última instância do Judiciário para assumir mais e mais sua função de corte constitucional ${ }^{31}$. Ou seja, foram anos de intenso debate sobre o sentido e a efetivação da CF exatamente porque, de um lado, reformas institucionais permitiram que o STF pudesse progressivamente passar a esse papel, e, de outro, porque o fim do ciclo de reformas iniciado no governo FHC parece ter se encerrado já no primeiro mandato de Lula, dando certa estabilidade ao conjunto do texto constitucional32.

Ou seja, a coincidência de reformas institucionais e de um novo ambiente político permitiram que pela primeira vez a CF pudesse se tornar de fato o objeto por excelência da atividade do STF. E, não por acaso, esse foco no Judiciário coincide ainda com o que se poderia chamar de uma onda de racionalização do Judiciário, representada por muitas medidas administrativas, mas, principalmente, pela criação do CNJ, em 2005. Não temos notícia de um período anterior da história brasileira em que o Judiciário enquanto tal tenha sido objeto de constante e amplo debate público.

A partir dessas considerações, acreditamos que se torna possível recolocar o problema de fundo envolvido nas ideias de "judicialização da política" e de "ativismo judicial" em novos termos. Deixando de lado o normativismo presente nessas noções, o que surge diante dos olhos é um processo de desenvolvimento das instituições democráticas que ainda vai encontrar nos conflitos sociais e políticos em curso respostas para questões como separação de poderes, funcionamento interno do Judiciário, ou mesmo o que virá a ser compreendido como "direito" e "direitos". E que, portanto, é impossível compreender esse processo em toda a sua complexidade sem que a categoria mesma de "esfera pública" passe a desempenhar aí um papel decisivo. Ou seja, em lugar de partir de uma concepção prévia sobre o lugar que deve ocupar o Judiciário na divisão de poderes, por exemplo, cabe acompanhar a maneira pela qual vai ser concretamente construída a noção nacional da "independência" entre os poderes bem como o mandamento de serem "harmônicos entre si", segundo diz o texto constitucional.

Não há decisão do STF que não seja aplaudida, contestada, criticada. E um dos pontos centrais do debate é justamente o do estabelecimento dos limites de uma corte constitucional e de seu papel no sistema político em sentido amplo. Também no âmbito aparentemente restrito à organização interna do Judiciário, os conflitos tomam proporções inesperadas. As próprias medidas tomadas pelo STF para concentrar e controlar a interpretação da Constituição põem a nu conflitos entre instâncias antes encobertos. Em um sistema misto de controle constitucional como é o brasileiro, essa tensão é permanente. 
O que não se mostrou até agora ruim. Não se trata de eliminar a tensão, mas de regrá-la da maneira mais democraticamente aberta possível, de tal modo que ela se torne produtiva para a administração da justiça e para o próprio debate público.Apenas para dar um exemplo entre muitos: assim como as liminares de primeira instância em boa medida salvaram a economia do país de um colapso quando da vigência do Plano Collor, o mesmo exercício no que diz respeito à garantia de acesso a remédios e tratamentos de saúde ganhou tal dimensão que acabou por se tornar um problema para a administração do orçamento público.

Como se vê por esses exemplos, abandonar a visão que embasa as ideias de "judicialização da política" e de "ativismo judicial" não significa abdicar de qualquer pretensão normativa. Significa apenas dar um passo atrás em relação a uma teoria normativa por demais determinada, que bloqueia tanto uma boa descrição dos conflitos como o surgimento de alternativas para encontrar as melhores fórmulas institucionais de seu regramento democrático.

MARCOS NOBRE é professor do departamento de Filosofia da Unicamp e pesquisador do Cebrap. JOSÉ RODRIGO RODRIGUEZ é pesquisador do Cebrap e editor da revista Direito GV.

Recebido para publicação em 1 de novembro de 2011.

\section{NOVOS ESTUDOS}

CEBRAP

91, novembro 2011

pp. 5-20 